\title{
Using area-level measures of social determinants of health to deliver improved and effective health care
}

\author{
Pallavi Jonnalagadda $^{1,2} \wedge$, Christine M. Swoboda ${ }^{1,3} \wedge$, Naleef Fareed ${ }^{1,2} \wedge$ \\ ${ }^{1}$ CATALYST - The Center for the Advancement of Team Science, Analytics, and Systems Thinking, College of Medicine, The Ohio State \\ University, Institute for Behavioral Medicine Research, 460 Medical Center Dr., Columbus, OH, USA; ${ }^{2}$ Department of Biomedical Informatics, \\ College of Medicine, The Ohio State University, Columbus, OH, USA; ${ }^{3}$ Department of Family and Community Medicine, College of Medicine, \\ The Ohio State University, Columbus, OH, USA \\ Contributions: (I) Conception and design: All authors; (II) Administrative support: None; (III) Provision of study materials or patients: None; (IV) \\ Collection and assembly of data: None; (V) Data analysis and interpretation: None; (VI) Manuscript writing: All authors; (VII) Final approval of \\ manuscript: All authors. \\ Correspondence to: Christine M. Swoboda, PhD, MS. CATALYST - The Center for the Advancement of Team Science, Analytics, and Systems \\ Thinking, College of Medicine, The Ohio State University, Room 502, Institute for Behavioral Medicine Research, 460 Medical Center Dr., \\ Columbus, OH 43210, USA. Email: Christine.Swoboda@osumc.edu.
}

\begin{abstract}
There is growing emphasis on social determinants of health $(\mathrm{SDoH})$ and their role in health care outcomes and health care delivery. Despite the importance of SDoH in determining individual health, this information is not routinely or systematically captured during clinical encounters. Providers cite lack of time, hesitation to ask patients for personal information, and lack of confidence in addressing social risk factors as barriers to the routine collection and use of SDoH in clinical practice. SDoH have been operationalized as composite scores of measures spanning several domains such as transport, income, crime, housing, and built environment at the area level. Living in deprived neighborhoods has been associated with adverse health outcomes. Several national and international efforts have focused on using area-level measures of SDoH to describe area-level deprivation information, or its counterpart, opportunity that measures potential for human progress, to communicate implications for individual and population health outcomes. We provide an overview of the current state of the field to orient readers to area-level measures of SDoH. We briefly discuss potential applications and limitations of area-level SDoH, as well as, implications for health care and health policy. Our overview is likely to help with the design and evaluation of health care interventions that aim to use area-level measures of SDoH.
\end{abstract}

Keywords: Area-level deprivation; poverty areas; social determinants of health (SDoH); healthcare disparities; medically underserved area; population health management

Received: 10 July 2020; Accepted: 20 November 2020; Published: 25 December 2020.

doi: $10.21037 /$ jhmhp-20-100

View this article at: http://dx.doi.org/10.21037/jhmhp-20-100

\section{Introduction}

Social determinants of health $(\mathrm{SDoH})$ are "the conditions in the places, where people live, learn, work, and age" (1). A combination of interrelated trends in public health have renewed interest in examining the "place" effect (2). First, clinical care explains $10 \%$ to $20 \%$ of health outcomes (3). Second, neighborhood characteristics may help in understanding the causes of social inequalities. Three,

\footnotetext{
^ ORCID: Pallavi Jonnalagadda: 0000-0002-2322-3229; Christine M. Swoboda: 0000-0002-2085-2126; Naleef Fareed: 0000-0001-87641625 .
} 
advances in computing power, geographic information systems (GIS), and statistical techniques like multilevel modeling allow for more sophisticated and detailed examination than in the past (2). SDoH can be assessed at the individual as well as the area level. The purpose of this report is to provide an introduction to area-level $\mathrm{SDoH}$ measured as deprivation or opportunity, give a brief description of area-level SDoH in the United States, and discuss current and potential applications of area-level SDoH measures in health care.

\section{Area-level deprivation or area-level opportunity}

Deprivation is "a state of observable and demonstrable disadvantage relative to the local community or the wider society or nation" (4). Opportunity, often contrasted with deprivation, is defined as "a range of circumstances that open doors to economic mobility and human progress" (5). Poverty and deprivation, though used interchangeably, are distinct. Deprivation refers to people's unmet needs and poverty refers to a lack of resources to meet those needs. Results from the Whitehall II study illustrated by the differential effects of neighborhood socioeconomic status. Individual poverty while living in an affluent neighborhood was not associated with negative health consequences, whereas living in a deprived neighborhood was associated with adverse health outcomes among poorer individuals (6). Area-level deprivation reflects aggregate measures of $\mathrm{SDoH}$ at the neighborhood level. Indeed, the role of neighborhood has been highlighted by the Moving to Opportunity experiment. Neighborhoods that children grew up in influenced prospects for upward income mobility in adulthood (7).

\section{Area-level SDoH in the United States}

SDoH have been operationalized as composite scores of indicators spanning several domains such as transport, income, crime, housing, etc. at the geographic level. These scores in turn reflect deprivation or opportunity. Area-level measures of SDoH have long been in use in countries like New Zealand and the United Kingdom. The New Zealand Index of Deprivation (NZDep), now in its fifth iteration, has been used for guiding resource allocation, community advocacy, and research. NZDep is used in capitation funding formulae for primary health care services, District Health Boards, and social services (8). Similarly, indices of multiple deprivation have been developed for each of the countries in the United Kingdom (9) and integrated in health care delivery.

A variety of area-level measures of $\mathrm{SDoH}$ have been developed in the US, some are national in scope, while others are specific to individual states. Neighborhoods have been operationalized based on administrative definitions as census tracts (CT), census block groups, or zip codes (2). The National Opportunity Index is a composite score of measures of education, economy, health, and community. It was developed to aid policymakers to identify and increase opportunity at the county and state levels (5). The Social Vulnerability Index (SVI) developed by the Centers for Disease Control and Prevention (CDC) used 15 variables at the CT level. The SVI was created to aid local officials in identifying the support communities would require in preparing for or recovering from disasters (10). The Area Deprivation Index (ADI) used US Census data at the CT level to calculate a score of deprivation (11). It has been adapted to reflect deprivation at the census block group level as a measure of neighborhood ADI. Studies using neighborhood ADI have shown higher readmission among Medicare patients living in the top $15 \%$ deprived neighborhoods. Further, compared to patients living in less deprived neighborhoods, those living in highly deprived neighborhoods were $70 \%$ more likely to be readmitted to the hospital within 30 days $(12,13)$. Together, these studies suggest that there is a certain level of supportive services necessary for communities, which once met, outcomes like readmission tend to be driven by individual-level factors.

The Utah ADI and the Ohio Opportunity Index (OOI) are two examples of area-level $\mathrm{SDoH}$ measures at the state level. The Utah ADI has been used in a "learning healthcare" system for community needs assessment, identifying high risk patients for care management and evaluating the impact of deprivation on the treatment of hypertension (14). Developed by the Ohio Department of Medicaid and researchers at The Ohio State University, the OOI was created to provide insights about patients' $\mathrm{SDoH}$ to health care providers and provide policymakers with information to make better decisions to alleviate health disparities across the state. OOI is a composite of seven domains-transportation, education, employment, housing, health, access to services, and crime (15).

Deprivation was reframed as opportunity based on feedback from the project sponsors. The OOI score is low for areas of high deprivation and high for areas of low deprivation (15). Linking the OOI scores for CTs with locations of service provision and specific health outcomes 
could aid in targeting areas in need of resources.

\section{SDoH in healthcare in the United States}

Two trends have renewed focus on $\mathrm{SDoH}$ in the United States. First, the measurement of health care outcomes instead of health care processes. Second, the realignment of health care from a volume-based to a value-based system $(16,17)$. Patients' ability to manage their health is affected by nonmedical factors such as the neighborhood they live in, which has implications for setting treatment goals and care delivery. SDoH may be negatively or positively associated with health. Social risk, sometimes used synonymously with $\mathrm{SDoH}$, refers to adverse social conditions associated with health. Social need, on the other hand, depends on individual preferences and priorities underscoring shareddecision making between patient and provider (18).

Individuals with unmet social needs tend to have poor control of hypertension, diabetes, and cholesterol, and have higher Emergency Department (ED) utilization (19). Therefore, hospitals, clinicians, and Accountable Care Organizations (ACO) caring for a large proportion of patients with social risk factors may be unfairly penalized, further exacerbating disparities. In response, the National Quality Forum (NQF) revised its proscription against adjustment for sociodemographic factors. Upon reviewing the evidence, the NQF recommended adjustment for some measures affected by SDoH like glycemic control, and against adjustment for others such as central line infections, which are largely under hospital control (16).

Despite the importance of $\mathrm{SDoH}$ in determining an individual's health, this information is not routinely or systematically captured during clinical encounters. In 2014, the Institute of Medicine (now the National Academy of Medicine) recommended the collection of a minimum of $10 \mathrm{SDoH}$ and one neighborhood-level SDoH (20). In a national network of 100 community health centers, $50 \%$ of the screening for $\mathrm{SDoH}$ occurred in four centers alone. Of the seven recommended domains, half the screenings included responses to only one domain (21). The debate regarding universal and comprehensive screening for $\mathrm{SDoH}$ during the clinical encounter is ongoing (22). Increased physician burden in recording $\mathrm{SDoH}$ that takes away time spent on patient care is a growing concern (23). Further, physicians have expressed concerns over making the patient uncomfortable asking for social risk factors, lack of direction in using the collected SDoH information, not having appropriate resources or infrastructure to address social risk factors, and lack of confidence in their capacity to address SDoH $(22,24)$. Furthermore, the development of screening tools for $\mathrm{SDoH}$ has outpaced studies of their reliability and validation. As a result, screening positive on current $\mathrm{SDoH}$ tools may not meet a threshold that would warrant assistance according to the patient (25).

\section{Applications of area-level SDH}

Systematic SDoH collection is a time-consuming and expensive undertaking. It requires provider training, building a referral system, fostering relationships with social services organizations, and integrating SDoH collection tools and electronic inventories into the system (26). Another critical step is the creation of workflows for administering an $\mathrm{SDoH}$ assessment, identifying care team members performing the SDoH assessment, and tracking of referrals and follow-ups (27). In lieu of collecting SDoH information from patients, the wealth of area-level measures of SDoH may be leveraged and incorporated into the electronic health record (EHR) (28). Area-level measures of deprivation have been successfully used in New Zealand and the United Kingdom to deliver health care (29). It is interesting to note that the United Kingdom uses arealevel measures of $\mathrm{SDoH}$ despite a health system that can potentially facilitate routine capture of individual-level $\mathrm{SDoH}(30)$.

The availability of aggregated area-level measures of SDoH or "community vital-signs" in the EHR enable both patients and providers to engage in patient-centered and community-oriented care that factors the neighborhood context (31). For example, the Utah Area-Deprivation Index serves as a proxy for patient-level SDoH (14). This approach may be valuable to health systems with limited resources to collect patient-level SDoH. The Population Health Assessment Engine (PHATE) is a mapping tool that integrates SDoH and clinical data. PHATE has been used to map the geographic distribution of individuals screening positive for food insecurity to make appropriate referrals to community resources (32). High-cost and high-utilizers of health care called "hot-spotters" have been managed with care coordination (33). However, there is evidence suggesting that targeting hot-spotters may not contribute to substantial cost savings (34). As hot-spotters may live in deprived communities, "cold-spotting" such communities for the purpose of designing interventions to better link primary care with social services and public health may in turn decrease both cold spots and hot spots (35). Healthcare 
systems can use area-level measures of SDoH to focus their limited resources on identifying and addressing disparities in cold spots. In a study of the relationship between an areabased measure of breast cancer screening and late stage breast cancer (LSBC) in Appalachia, higher deprivation measured by the ADI was associated with higher incidence of LSBC. Area deprivation better explained area-based effects of poverty than socio-economic status. Further, better regional access to breast cancer screening was associated with lower incidence of LSBC. Overall, the study emphasized the importance of developing policies that formalize links among screening centers, health care providers, and community advocacy groups in underserved areas to promote cancer screening (36).

Geospatial approaches to quantify and visualize SDoH not only better capture the complexity and spatial heterogeneity (37), but also facilitate intuitive use by stakeholders. Previously, GIS was successfully used within a primary care network to map practice management and population data, thereby revealing variation between actual clinic service areas and the medically underserved areas. A need for technical assistance and dynamic mapping was expressed at the time (38). Today, many area-level SDoH have been operationalized as dashboards for intuitive use by stakeholders. The SVI is available as an interactive map (10); the neighborhood ADI has been visualized as the Neighborhood Atlas (39); and the OOI has been visualized as an interactive dashboard (15).

The US lags behind other countries in the use of arealevel measures of $\mathrm{SDoH}$ for health policy and reimbursement purposes. Some notable exceptions include the Massachusetts Managed Care Model and the ACO with Medicaid waiver in Hennepin Health $(\mathrm{HH})$ in Minnesota (30). The Massachusetts model was created after the Medicare Access and Children's Health Insurance Plan Reauthorization Act of 2015, which emphasizes value-based rather than volumebased care. Risk adjustment was performed to allocate funds to health plans. Policymakers in Massachusetts combined $\mathrm{SDoH}$ and diagnostic codes to create a reimbursement model. In addition to demographic factors and individuallevel SDoH, a neighborhood stress score was incorporated into the model (40). The HH model focused on adult patients without dependents living at or below $75 \%$ of the federal poverty level. Six months of enrollment into the HH ACO reduced hospitalizations and ED use, and increased dental visits and use of primary care. While the study did not use area-level composite measures of SDoH, a combination of area-level indicators and individual-level
SDoH were employed (41).

The importance of $\mathrm{SDoH}$ in health care is indisputable. Nevertheless, evidence is emerging of a gap between the number of patients screening positive for social risk factors and those actually desiring assistance (42) with implications for health systems planning on implementing screening for $\mathrm{SDoH}$. While this may be attributable to inadequate testing of the psychometric properties of the SDoH screening tool, it is likely patients do not consider the clinical encounter as the right setting to discuss social needs (42). It is important to gain a better understanding of the factors associated with accepting social care from health care providers. Further, area-level SDoH should be evaluated and tested in interventions as knowledge of the pathways linking $\mathrm{SDoH}$ and health outcomes is limited $(43,44)$.

\section{Limitations of using area-level SDH}

Area-level measures of SDoH reflect neighborhood levels of deprivation and not levels of deprivation of the individuals residing there. Therefore, deprived areas may have a large proportion of people who are not deprived at the individual level and vice versa. Consequently, a patient's residence in a deprived neighborhood must not be conflated with social risk. Although it is important to define arealevel deprivation to pursue area-based solutions, other kinds of solutions to address social risk factors should not be overlooked (9). Reliance on census data to construct arealevel SDoH poses a limitation as this data is updated in tenyear cycles. However, other sources of administrative data have been successfully used to update and construct arealevel measures of SDoH. Composite indices are constructed by combining different indicators in a weighted fashion, therefore changing the indicators may affect the composite index score. Experts have cautioned that the creation of arealevel composite measures is a process fraught with debates and complex decision-making. Therefore, users must bear in mind that indices and the dashboards that visualize them are shaped by technical, design, social and political considerations, which may not be entirely objective (45). Lastly, debate persists regarding the appropriateness of the dimensions of deprivation and the geographic unit at which measurements of SDoH are made (46).

\section{Conclusions}

Rising interest in the "place" effect and heath inequities has shifted the conversation to innovation in health care delivery 
and collaboration between healthcare organizations, public health, and social services. While more evidence is needed pertaining to the collection, validity, and use of individuallevel $\mathrm{SDoH}$ in improving healthcare, area-level measures of SDoH represent a rich resource of readily-available data that may be used to improve health care delivery.

\section{Acknowledgments}

Funding: None.

\section{Footnote}

Provenance and Peer Review: This article was commissioned by the editorial office, Fournal of Hospital Management and Health Policy for the series "Innovations and Practices that Influence Patient-Centered Health Care Delivery". The article has undergone external peer review.

Conflicts of Interest: All authors have completed the ICMJE uniform disclosure form (available at http://dx.doi. org/10.21037/jhmhp-20-100). The series "Innovations and Practices that Influence Patient-Centered Health Care Delivery" was commissioned by the editorial office without any funding or sponsorship. NF served as the unpaid Guest Editor of the series and serves as an unpaid editorial board member of Fournal of Hospital Management and Health Policy from December 2019 to November 2021. The authors have no other conflicts of interest to declare.

Ethical Statement: The authors are accountable for all aspects of the work in ensuring that questions related to the accuracy or integrity of any part of the work are appropriately investigated and resolved.

Open Access Statement: This is an Open Access article distributed in accordance with the Creative Commons Attribution-NonCommercial-NoDerivs 4.0 International License (CC BY-NC-ND 4.0), which permits the noncommercial replication and distribution of the article with the strict proviso that no changes or edits are made and the original work is properly cited (including links to both the formal publication through the relevant DOI and the license). See: https://creativecommons.org/licenses/by-nc-nd/4.0/.

\section{References}

1. (WHO) World Health Organization. WHO I About social determinants of health. Available online: https:// www.who.int/social_determinants/sdh_definition/en/

2. Diez Roux AV. Neighborhoods and health: where are we and were do we go from here? Revue d'Epidemiologie et de Sante Publique 2007;55:13-21.

3. Hood CM, Gennuso KP, Swain GR, et al. County Health Rankings: Relationships Between Determinant Factors and Health Outcomes. Am J Prev Med 2016;50:129-35.

4. Townsend P. Deprivation. J Soc Policy 1987;16:125-46.

5. Opportunity Index 2015: Summary of findings for states \& counties. Opportunity Nation. 2015. Available online: http://opportunityindex.org/wp-content/ uploads/2015/10/2015-Opportunity-Index-Report.pdf

6. Stafford M, Marmot M. Neighbourhood deprivation and health: does it affect us all equally? Int J Epidemiol 2003;32:357-66.

7. Chetty R, Hendren N, Katz LF. The Effects of Exposure to Better Neighborhoods on Children: New Evidence from the Moving to Opportunity Experiment. Am Econ Rev 2016;106:855-902.

8. Atkinson J, Salmond C, Crampton P. NZDep2013 index of deprivation. Wellington: Department of Public Health, University of Otago; 2014.

9. Noble M, Wright G, Smith G, et al. Measuring multiple deprivation at the small-area level. Environment and Planning A 2006;38:169-85.

10. Social Vulnerability Index. Centers for Disease Control and Prevention. 2018. Available online: https://svi.cdc.gov/

11. Singh GK. Area deprivation and widening inequalities in US mortality, 1969-1998. Am J Public Health 2003;93:1137-43.

12. Kind AJ, Jencks S, Brock J, et al. Neighborhood socioeconomic disadvantage and 30-day rehospitalization: a retrospective cohort study. Ann Intern Med 2014;161:765-74.

13. Kind AJH, Jencks S, Brock J, et al. Neighborhood socioeconomic disadvantage and 30-day rehospitalization: a retrospective cohort study. Ann Intern Med 2014;161:765-74.

14. Knighton AJ, Savitz L, Belnap T, et al. Introduction of an area deprivation index measuring patient socioeconomic status in an integrated health system: implications for population health. EGEMS (Wash DC) 2016;4:1238.

15. Fareed N, Swoboda CM, Jonnalagadda P, et al. Visualizing Opportunity Index Data Using a Dashboard Application: A Tool to Communicate Infant Mortality-based Area Deprivation Index Information. Appl Clin Inform 2020;11:515-27. 
16. Fiscella K, Burstin HR, Nerenz DR. Quality measures and sociodemographic risk factors: to adjust or not to adjust. JAMA 2014;312:2615-6.

17. VanLare JM, Conway PH. Value-Based Purchasing-National Programs to Move from Volume to Value. N Engl J Med 2012;367:292-5.

18. Alderwick H, Gottlieb LM. Meanings and Misunderstandings: A Social Determinants of Health Lexicon for Health Care Systems. Milbank Q 2019;97:407-19.

19. Berkowitz SA, Hulberg AC, Hong C, et al. Addressing basic resource needs to improve primary care quality: a community collaboration programme. BMJ Qual Saf 2016;25:164-72.

20. Adler NE, Stead WW. Patients in context--EHR capture of social and behavioral determinants of health. N Engl J Med 2015;372:698-701.

21. Cottrell EK, Dambrun K, Cowburn S, et al. Variation in Electronic Health Record Documentation of Social Determinants of Health Across a National Network of Community Health Centers. Am J Prev Med 2019;57:S65-S73.

22. Garg A, Boynton-Jarrett R, Dworkin PH. Avoiding the Unintended Consequences of Screening for Social Determinants of Health. JAMA 2016;316:813-4.

23. Davidson KW, McGinn T. Screening for Social Determinants of Health: The Known and Unknown. JAMA 2019;322:1037-8.

24. Schickedanz A, Hamity C, Rogers A, et al. Clinician Experiences and Attitudes Regarding Screening for Social Determinants of Health in a Large Integrated Health System. Med Care 2019;57:S197-S201.

25. Henrikson NB, Blasi PR, Dorsey CN, et al. Psychometric and Pragmatic Properties of Social Risk Screening Tools: A Systematic Review. Am J Prev Med 2019;57:S13-S24.

26. Thomas-Henkel C, Schulman M. Screening for social determinants of health in populations with complex needs: implementation considerations. Center for Health Care Strategies; 2017.

27. Nuruzzaman N, Broadwin M, Kourouma K, et al. Making the social determinants of health a routine part of medical care. J Health Care Poor Underserved 2015;26:321-7.

28. DeVoe JE. When and How Do We Need Permission to Help Patients Address Social Risk? J Am Board Fam Med 2020;33:176.

29. Phillips RL, Liaw WR, Crampton P, et al. How Other Countries Use Deprivation Indices-And Why The United States Desperately Needs One. Health Aff (Millwood)
2016;35:1991-8.

30. Huffstetler AN, Phillips RL. Payment Structures That Support Social Care Integration With Clinical Care: Social Deprivation Indices and Novel Payment Models. Am J Prev Med 2019;57:S82-S88.

31. Bazemore AW, Cottrell EK, Gold R, et al. "Community vital signs": incorporating geocoded social determinants into electronic records to promote patient and population health. J Am Med Inform Assoc 2016;23:407-12.

32. Lichkus J, Liaw WR, Phillips RL. Utilizing PHATE: A Population Health-Mapping Tool to Identify Areas of Food Insecurity. Ann Fam Med 2019;17:372.

33. Gawande A. Finding Medicine's Hot Spots I The New Yorker. The New Yorker. 2011.

34. Lee NS, Whitman N, Vakharia N, et al. High-Cost Patients: Hot-Spotters Don't Explain the Half of It. J Gen Intern Med 2017;32:28-34.

35. Westfall JM. Cold-Spotting: Linking Primary Care and Public Health to Create Communities of Solution. J Am Board Fam Med 2013;26:239.

36. Anderson RT, Yang TC, Matthews SA, et al. Breast Cancer Screening, Area Deprivation, and Later-Stage Breast Cancer in Appalachia: Does Geography Matter? Health Serv Res 2014;49:546-67.

37. Kolak M, Bhatt J, Park YH, et al. Quantification of Neighborhood-Level Social Determinants of Health in the Continental United States. JAMA Netw Open 2020;3:e1919928.

38. Bazemore A, Phillips RL, Miyoshi T. Harnessing Geographic Information Systems (GIS) to Enable Community-Oriented Primary Care. J Am Board Fam Med 2010;23:22.

39. Kind AJH, Buckingham WR. Making NeighborhoodDisadvantage Metrics Accessible - The Neighborhood Atlas. N Engl J Med 2018;378:2456-8.

40. Ash AS, Mick EO, Ellis RP, et al. Social Determinants of Health in Managed Care Payment Formulas. JAMA Intern Med 2017;177:1424-30.

41. Vickery KD, Shippee ND, Menk J, et al. Integrated, Accountable Care For Medicaid Expansion Enrollees: A Comparative Evaluation of Hennepin Health. Med Care Res Rev 2020;77:46-59.

42. De Marchis EH, Alderwick H, Gottlieb LM. Do Patients Want Help Addressing Social Risks? J Am Board Fam Med 2020;33:170.

43. Braveman P, Gottlieb L. The Social Determinants of Health: It's Time to Consider the Causes of the Causes. Public Health Rep 2014;129:19-31. 
44. Frakt AB, Jha AK, Glied S. Pivoting from decomposing correlates to developing solutions: An evidence-based agenda to address drivers of health. Health Serv Res 2020;55:781-6.

45. Kitchin R, Lauriault TP, McArdle G. Knowing and governing cities through urban indicators, city

doi: $10.21037 /$ jhmhp-20-100

Cite this article as: Jonnalagadda P, Swoboda CM, Fareed $\mathrm{N}$. Using area-level measures of social determinants of health to deliver improved and effective health care. J Hosp Manag Health Policy 2020;4:38. benchmarking and real-time dashboards. Reg Stud Reg Sci 2015;2:6-28.

46. Santos ME, Santos G. Composite indices of development. In: Bruce CA, Ravi K, David MM, et al. editors. Oxford University Press; 2014. 